\title{
Assessment of Doppler ultrasound to measure systolic and diastolic blood pressures in infants and young children
}

\author{
R. K. WHYTE, A. M. ELSEED, C. B. FRASER, E. A. SHINEBOURNE, and M. de SWIET \\ From the Department of Paediatrics, Brompton Hospital and Cardiothoracic Institute, London
}

\begin{abstract}
Whyte, R. K., Elseed, A. M., Fraser, C. B., Shinebourne, E. A., and de Swiet, M. (1975). Archives of Disease in Childhood, 50, 542. Assessment of Doppler ultrasound to measure systolic and diastolic blood pressures in infants and young children. A recently developed instrument uses the Doppler shift technique to detect vessel wall movement, and it has been suggested that in conjunction with a conventional sphygmomanometer systolic and diastolic blood pressures can be measured. A controlled study was carried out in 20 children recovering from cardiac surgery where direct intra-arterial measurements (one observer) were compared with independent measurements using the Doppler instrument (2 observers). Systolic pressures measured directly and by Doppler technique correlated well and there was no significant difference between intra-arterial and indirect measurements whether the latter were taken by doctors or by nurses. In contrast, direct and indirect diastolic pressure measurements correlated poorly and were significantly overestimated with a mean difference of $6.25 \mathrm{mmHg}$ (range +25 to -10 ) for doctors, and $4.25 \mathrm{mmHg}$ (range +20 to -10 ) for nurses. Thus, the instrument adequately measured systolic blood pressure, but in our hands did not give precise measurements for diastolic blood pressure.
\end{abstract}

We have previously shown that measurement of systolic pressures in children by means of the Parks 802 Doppler instrument did not exhibit any significant difference from direct intra-arterial pressure measurements (Elseed, Shinebourne, and Joseph, 1973). However, the Parks instrument did not allow measurement of diastolic pressure, a facility reputedly available with the Arteriosonde (Roche). $†$

In this study, systolic and diastolic pressures obtained with the latter instrument were again compared with direct measurements taken via arterial cannulation.

\section{Method}

All studies were carried out on children in the postoperative period after cardiac surgery. Children with coarctation, Blalock-Taussig shunts, or other conditions

Received 2 December 1974.

^Parks Electronics Laboratory. Model No. 802. Distributed in the UK by Instrumentarium Ltd.

tRoche Bio-Electronics. Model 1011. Distributed in the UK by Kontron Instruments Ltd., Welwyn Garden City. which might be expected to produce unequal pressures in the arms were excluded. 20 children, aged 5 days to 9 years, mean age 2 years 4 months, were studied.

For routine postoperative monitoring, direct intraarterial blood pressure was measured in each child via an indwelling intra-arterial polyethylene cannula (ID $0.70 \mathrm{~mm}$ ) in the radial artery. This was connected to a Bell and Howell pressure transducer (4-327-L223) via a polyethylene connexion tube (length $140 \mathrm{~cm}$, ID $2 \mathrm{~mm}$ ) filled with normal saline. The cannula was perfused at a rate of $2-3 \mathrm{ml} / \mathrm{h}$ with Hartmann's solution using the Intraflo device* (Shinebourne and Pfitzner, 1973). The frequency response of the catheter-transducer system has been shown to be flat to $12 \mathrm{~Hz}$.

At a time when the infant's cardiovascular state was stable, the blood pressure was measured independently by two observers, a doctor and a nurse. All Arteriosonde measurements were made on the upper arm contralateral to the site of the indwelling catheter. All readings were taken after prior inflation of the cuff to $200 \mathrm{mmHg}$ followed by deflation at a rate not faster than $7 \mathrm{mmHg} / \mathrm{s}$. The first heart sound from the

^Sorenson Research Co., Salt Lake City, Utah. Manufactured in the UK by Simonsen \& Weel Ltd. 
Arteriosonde was taken as systolic pressure, and the point at which sounds became muffled was taken as the diastolic pressure. All measurements were taken to the nearest $5 \mathrm{mmHg}$.

Simultaneously, a third observer independently recorded direct intra-arterial blood pressure from the display unit.

\section{Results}

Systolic pressure. Fig. 1 shows the results of comparing systolic pressure measurements by Arteriosonde with simultaneous direct intra-arterial readings. There was good correlation between results obtained both by doctors $(r=0.88$, $P<0.001)$ and nurses $(r=0.87, P<0.001)$. Results obtained by doctors and nurses correlated well with each other $(r=0.95, P<0.001)$. Applying Student's ' $t$ ' test to paired observations, there was no significant difference between direct and indirect measurements.

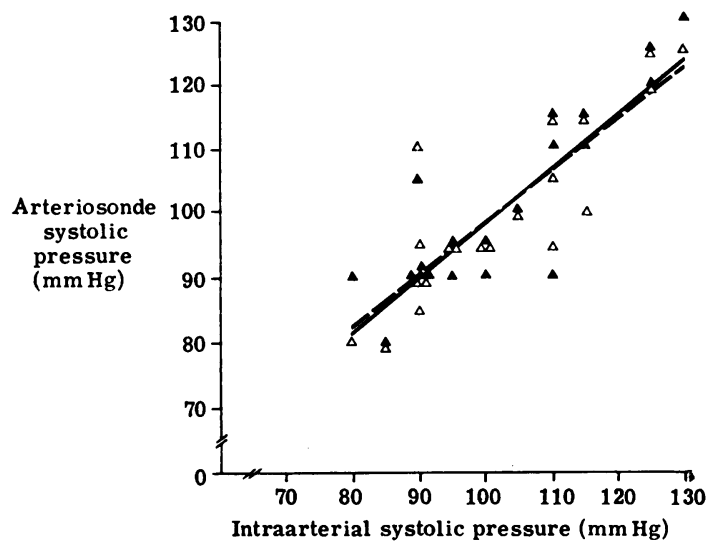

FIG. 1.-Systolic pressure measurements obtained with Arteriosonde compared with direct intra-arterial measurements. $\triangle$ Arteriosonde measurements by doctor; $\triangle A r-$ teriosonde measurements by nurse. - is the regression of doctor Arteriosonde on direct, where $y=0 \cdot 85 x$ $+13.2 \mathrm{mmHg}$. - - - is the regression of nurse Arteriosonde on direct, where $y=0.82 x+16.5 \mathrm{mmHg}$.

Diastolic pressure. Fig. 2 shows the results of comparing diastolic pressure measured by Arteriosonde with intra-arterial measurements. There was poor correlation between results obtained with Arteriosonde both by doctors $(r=0.51, P<0.05)$ and by nurses $(r=0.50, P<0.05)$. Furthermore, the Arteriosonde diastolic pressure was significantly higher than intra-arterial blood pressure (mean difference: doctors $6 \cdot 25 \mathrm{mmHg}$, range +25 to -10 ; nurses $4 \cdot 25 \mathrm{mmHg}$, range +20 to -10 ). However, results obtained by doctors and nurses compared well $(r=0 \cdot 89)$.

\section{Discussion}

Systolic and diastolic blood pressure measurements made using the Arteriosonde Doppler machine are here compared with direct intra-arterial measurements. As in our previous study with the Parks instrument, correlations of systolic pressure (Fig. 1) are good (Elseed et al., 1973). Correlations of diastolic pressures, however, are poor (Fig. 2), and the Arteriosonde considerably overestimates diastolic pressure. As duplicate measurements by nurse and doctor compare well, instrument error is more likely to be the case than observer error. Hochberg and Saltzman (1971) showed a high correlation between direct and Arteriosonde diastolic measurements in neonates. However, blind measurements were not made in their study, which may account for the difference from our findings.

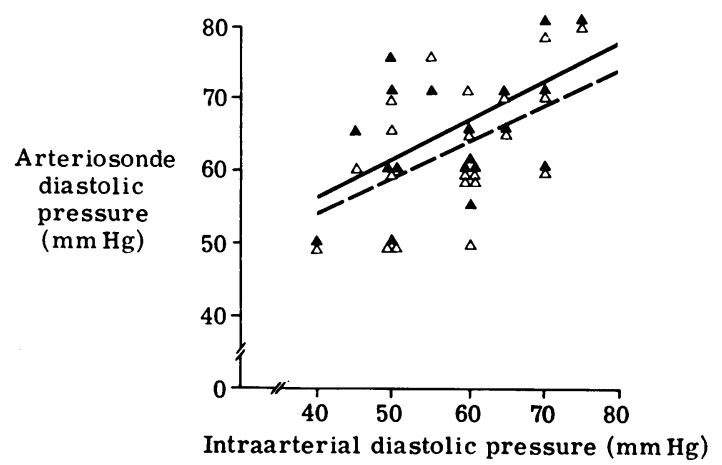

FIG. 2.-Diastolic pressure measurements obtained with Arteriosonde compared with direct intra-arterial pressures. $\triangle$ Arteriosonde measurements by doctor; $\triangle$ Arteriosonde measurements by nurse. - is the regression of doctor Arteriosonde on direct, where $y=0.45 x+38 \cdot 0$ $\mathrm{mmHg}$. - - - is the regression of nurse Arteriosonde on direct, where $y=0 \cdot 49 x+34 \cdot 4 \mathrm{mmHg}$.

Our nursing staff found the Arteriosonde simple to use when applied to the upper arm, but on small infants it was difficult to position the cuff and transducer over a lower limb pulse. We found it easier to use the Parks instrument (Elseed et al., 1973) which allowed the transducer to be positioned over the posterior tibial pulse while the cuff was inflated around the calf. This method allowed only systolic pressure measurements to be made.

In conclusion, we feel that the Arteriosonde gives reliable measurements of systolic pressure. We were less impressed by the accuracy of the machine when used for measuring diastolic pressures, and by its application for measuring systolic lower limb pressures in small infants. 
We thank Dr. A. Ducker, Sister E. M. Swift, and the nursing staff of the Paediatric Intensive Care Unit for help with measurements; and Elizabeth Thompson for help with the manuscript.

\section{REFERENCES}

Elseed, A. M., Shinebourne, E. A., and Joseph, M. C. (1973). Assessment of techniques for measurement of blood pressure in infants and children. Archives of Disease in Childhood, 48, 932.
Hochberg, H. M., and Saltzman, M. P. (1971). Accuracy of an ultrasound blood pressure instrument in neonates, infants, and children. Current Therapeutic Research, 13, 482.

Shinebourne, E. A., and Pfitzner, J. (1973). Continuous flushing device for indwelling arterial and venous cannulae. British fournal of Hospital Medicine, Equipment Supplement, 9, 64.

Correspondence to Dr. E. A. Shinebourne, Brompton Hospital, Fulham Road, London SW3 6HP.

The following articles will appear in future issues of this journal:

Annotation: Bacteriuria, reflux, and scarring. J. M. Smellie and I. C. S. Normand.

Personal practice: District paediatric day care. H. Marcovitch, H. T. Davenport, D. B. Grant, M. M. Liberman, and $H$. B. Valman.

Fat absorption by small babies fed two filled milk formulae. R. D. G. Milner, Y. Deodhur, C. R. Chard, and R. M. Grout.

Hyperbilirubinaemia and bacterial infection in the newborn: a prospective study. P-O. Chavalitdhamrong, M. B. Escobedo, L. L. Barton, H. Zarkowsky, and R. E. Marshall.

Hereditary anhidrotic ectodermal dysplasia: studies in a Nigerian family. J. B. Familusi, F. Jaiyesimi, C. O. Ojo, and E. B. Attah.

Urinary phenolic acid and alcohol excretion in the newborn. F.Karoum, C. R. J. Ruthven, and M. Sandler.

Peripheral gangrene in hypernatraemic dehydration of infancy. S. A. Comay and C. D. Karabus.

Do the right children have necropsies? Analysis of selected determinants. L. Munan, A. Kelly, and R. Cote. 